\title{
Cloudy corneas as an initial presentation of multiple myeloma
}

This article was published in the following Dove Press journal:

Clinical Ophthalmology

28 April 2014

Number of times this article has been viewed

\section{Priyanka Sharma' \\ Haifa A Madi' \\ Richard Bonshek ${ }^{2}$ \\ Stephen J Morgan'}

'Sunderland Eye Infirmary, Sunderland, UK; ${ }^{2}$ National Specialist Ophthalmic Pathology Service, Department of Histopathology, Manchester Royal Infirmary, Manchester, UK
Correspondence: Stephen J Morgan, FRCOphth, D.O. Consultant Ophthalmologist, Sunderland Eye Infirmary, Queen Alexandra Road, Sunderland, SR2 9HP, UK

Tel +44 I9I 5699075

Email stephen.morgan@chsft.nhs.uk
Summary: We report a case of previously unsuspected myeloma, presenting with cornea verticillata due to intracorneal paraprotein deposition.

History: An 85-year-old female presented via her optician with a 4-month history of cloudy vision. She had undergone an uneventful bilateral phacoemulsification surgery 7 years earlier. Extensive spiraling corneal epithelial opacification was noted on slit-lamp examination. On further investigation, she was found to have a previously unsuspected low-grade multiple myeloma. We established the nature of the corneal deposits with corneal epithelial biopsy histopathology and electron microscopy. It is very rare for multiple myeloma to present in this fashion. Ophthalmologists should be aware that such a presentation may rarely be due to systemic multiple myeloma.

Keywords: corneal crystals, multiple myeloma, crystalline keratopathy, vortex keratopathy

\section{Introduction}

Corneal deposits of various types have been described in multiple myeloma, monoclonal gammopathy, and essential cryoglobulinemia. ${ }^{1,2}$ There are only a very few case reports of corneal immunoglobulin (Ig) deposition. We present one such case in which there was intraepithelial deposition of corneal IgG-kappa. In addition, it is noteworthy that the presentation to the ophthalmologist was the presenting complaint leading to the diagnosis of myeloma.

\section{Case report}

An 85-year-old lady with bilateral cloudy corneas was referred to ophthalmology as an outpatient from her optometrist. She gave a 3-4 month history of cloudy vision, mainly in her right eye. She had undergone an uneventful bilateral phacoemulsification surgery 7 years earlier.

Her visual acuity at presentation was 6/7.5 OU. On examination, she had marked grayish intraepithelial corneal opacities in a pattern of hazy spiraling lines in both eyes (Figure 1). The corneal stroma and endothelium had normal appearance; there was no evidence of corneal edema. Specular microscopy was not possible. The anterior chamber depth and contents, intraocular lenses, posterior capsule, and fundus examination were normal.

She had a past medical history of ischemic heart disease and osteopenia. Her current medications were aspirin, simvastatin, lisinopril, codeine, and paracetamol.

Systemic investigation revealed a raised serum IgG with a kappa paraprotein band $(12.4 \mathrm{~g} / \mathrm{L})$ on serum protein electrophoresis (Figure 2$)$. The erythrocyte sedimentation 

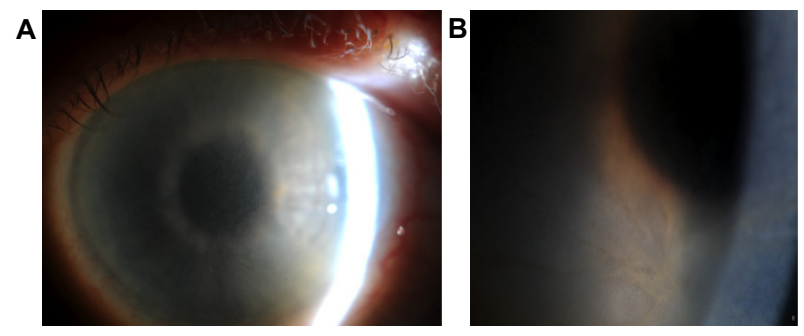

Figure I Clinical photographs of the right cornea.

Notes: (A) Subepithelial deposits extending toward the corneal center by fingerlike projections; (B) at higher magnification, depicting the spiral-like pattern known as corneal verticillata.

rate was raised ( $49 \mathrm{~mm} /$ hour), and there was a mild kidney impairment with raised urea $(8.1 \mathrm{mmol} / \mathrm{L})$ and raised creatinine $(118 \mu \mathrm{mol} / \mathrm{L})$. The random blood glucose, electrolytes, liver function, lipid profile, and calcium profile were normal. Urinary Bence Jones proteins were elevated. There was no evidence of Fabry disease as the lysosomal enzymes were all found to be normal.

She was referred to the Department of Haematology, Sunderland Royal Hospital, Sunderland, UK, and a bone marrow biopsy was carried out that showed increased plasma cells $(11 \%)$ with pink staining crystals in the cytoplasm. Free crystals were also seen. These findings were consistent with multiple myeloma.

A corneal epithelial biopsy was undertaken and subjected to further laboratory analysis. Immunohistochemistry of the corneal biopsy showed excessive amounts of kappa light chain staining, relative to lambda light chain staining. On transmission electron microscopy, there was evidence of intraepithelial intracellular and extracellular geometrically irregular hexagonal electron dense particles (Figure 3). These are typically found in crystalline keratopathy due to gammopathy. There was an absence of immunotactoid, a paraprotein also commonly present in these cases, but not detected in our case.

The patient was commenced on systemic chemotherapy with cyclophosphamide and dexamethasone. Six months later, there was significant improvement in corneal clarity (Figure 4).

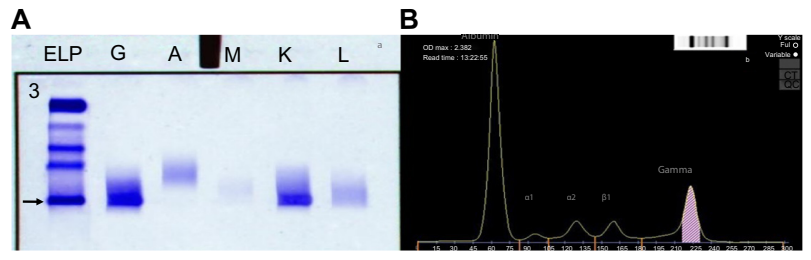

Figure 2 Serum immunofixation electrophoresis and its graphical representation. Notes: (A) ELP, G, A, M, K, and L. The arrow indicates the position of the monoclonal protein. (B) A large spike in the gamma region is shaded in pink.

Abbreviations: ELP, serum protein electrophoresis; G, immunoglobulin G; A, immunoglobulin A; M, immunoglobulin M; K, kappa light chain; L, lambda light chain.
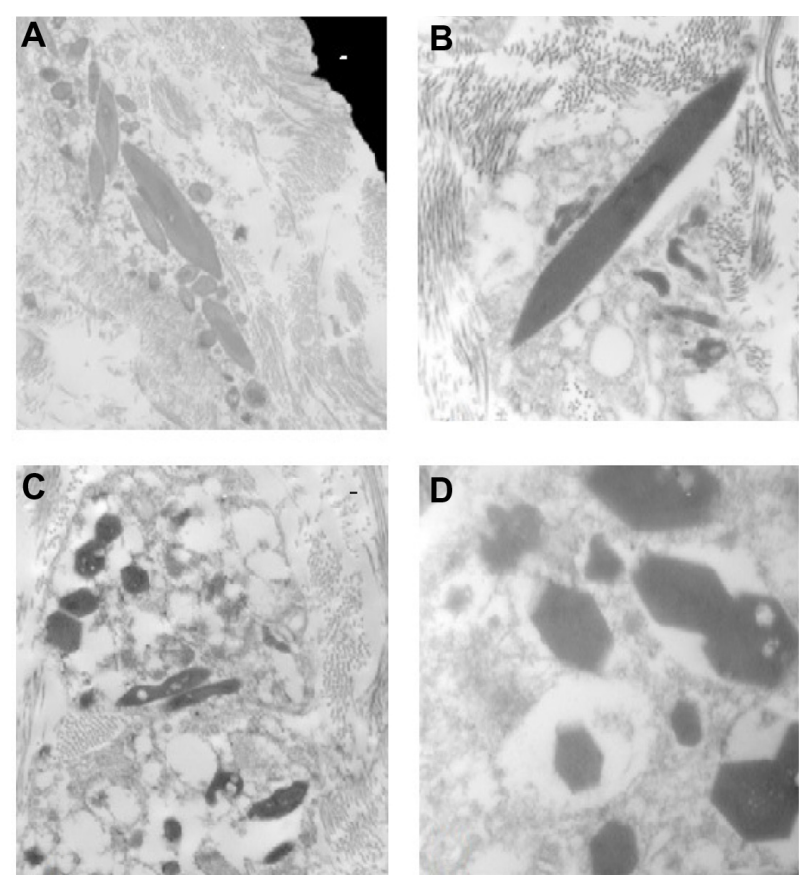

Figure 3 Electron microscopy of the corneal biopsy specimen.

Notes: (A) Numerous epithelial rod-shaped bodies (original magnification, $\times 7,200$ ). (B) Epithelial rod-shaped body at higher magnification (original magnification, $\times$ 19,000). (C) Numerous intracellular hexagonal-shaped bodies (original magnification, $\times 19,000)$. (D) Intracellular hexagonal-shaped bodies at higher magnification (original magnification, $\times 29,000$ ).

\section{Discussion}

Corneal epithelial disturbance in a spiraling pattern is variously known as cornea verticillata, vortex keratopathy, and hurricane keratopathy. Well-recognized causes include: Fabry disease ${ }^{3}$ drugs $^{4}$ (amiodarone, ${ }^{5}$ chloroquine, hydroxychloroquine, indomethacin, chlorpromazine, tamoxifen, meperidine); toxicity of topical medications; and ocular surface failure secondary to chemical and thermal burns, conjunctival malignancy, and cicatrizing conjunctivitis.

In myeloma, an intracorneal accumulation of Ig is welldescribed. Patients may be asymptomatic or complain of decreased vision, ${ }^{6}$ irritation, ${ }^{7}$ photophobia, ${ }^{8}$ and erosions. ${ }^{9,10}$ The corneal deposition can be crystalline, ${ }^{10-12}$ amorphous, ${ }^{6}$ or a combination.

Other ocular surface manifestations of multiple myeloma include repeated subconjunctival hemorrhages,${ }^{13}$ peripheral
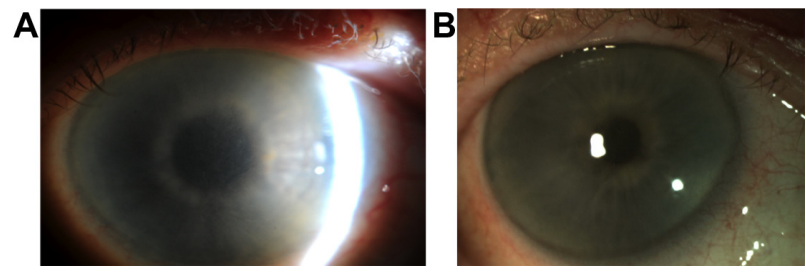

Figure 4 Before and after photographs of right cornea.

Notes: (A) Before: cloudy cornea at baseline. (B) After: after receiving treatment for myeloma the corneal cloudiness started improving. 
ulcerative keratitis, ${ }^{14}$ prominent corneal nerves, ${ }^{9}$ and band keratopathy. ${ }^{15}$

Our patient turned out to have intracorneal crystal deposition, although the crystals were too small to be seen on slit-lamp examination. Other causes of intracorneal crystal deposition include cystinosis, ${ }^{16}$ Schnyder crystalline corneal dystrophy, ${ }^{17}$ Bietti crystalline corneoretinal dystrophy, tyrosinemia, ${ }^{18}$ gout, and topical medications (fluoroquinolone). ${ }^{19}$

The pathophysiology of intracorneal crystal formation in multiple myeloma remains enigmatic. One theory is that the deposits result from elevated Ig levels in the tears and aqueous humor; ${ }^{20}$ another is that they enter the cornea from the limbal blood vessels; and a third is that the keratocytes themselves synthesize the precipitated Ig. Henderson et $\mathrm{al}^{21}$ discuss that some of the reasons for Ig deposition are: 1) an inherent propensity of some Ig or kappa light chains to crystallize; and 2) local factors in the cornea that may promote deposition, such as temperature, $\mathrm{pH}$, water content, and extracellular matrix deposition. The immunoglobulin substances have been found in serum, tears, urine, aqueous humor, cornea ${ }^{8,22}$ (subepithelial ${ }^{2,22,23}$ /intraepithelial ${ }^{10}$ tissues), and bone marrow.

This case is unusual because it is rare to have corneal deposition in multiple myeloma. It is even rarer for it to be the presenting complaint to an ophthalmologist. On searching the literature, we have found a total of 27 case reports of corneal Ig deposition in multiple myeloma. Of these, 17 were crystalline, ${ }^{7}$ four were amorphous ${ }^{25}$ two were hyaline, ${ }^{26}$ one was granular, ${ }^{27}$ and no tissue was obtained in three. This suggests that the corneal Ig distribution in multiple myeloma is frequently crystalline. Ig deposits can be both intracellular and extracellular. ${ }^{28}$ Another distinct pattern of involvement is an immunotactoid pattern. Stirling et $\mathrm{al}^{28}$ showed ultrastructural images of tubular paracrystalline structure of corneal immunoglobulin deposition which were later termed as "immunotactoid keratopathy" by Garibaldi. Garibaldi ${ }^{7}$ proposed the use of term "immunotactoid keratopathy" to describe corneal Ig deposits in tubular, electron-dense, crystalloid deposits with central lucent core on electron microscopy (they reported two such cases with Ig kapa deposits).

Ig-kappa deposition in the cornea was seen in eleven cases of multiple myeloma, ${ }^{7}$ although IgG gamma globulin was deposited in three corneas, and IgG lambda was deposited in three cases - with IgG-kappa and lambda in one case, IgD in one case, and IgA in one case. The type of Ig deposited in the cornea was not clarified in seven cases. This suggests that Ig deposition in the cornea is most frequent in the kappa variety of multiple myeloma.
Ig-kappa distribution can affect different corneal layers. It was reported to be deposited in: all layers of the cornea in four cases; ${ }^{20,29-31}$ only stromal involvement in three cases, ${ }^{8,12}$ only epithelial involvement in two cases; ${ }^{11,32}$ epithelium and stromal $^{6}$ involvement in one case; and endothelium and Descemet's membrane ${ }^{33}$ involvement in one case.

Corneal deposition of immunoglobulins in multiple myeloma is rarely in a vortex pattern. Two cases of vortex keratopathy in multiple myeloma have been previously reported. Auran et $\mathrm{al}^{32}$ described a case of crystalline keratopathy in a vortex pattern in a patient with multiple myeloma. However, they did not obtain any pathological material. Their patient had already undergone bilateral phacoemulsification 7 years previously and later developed an endocapsular hematoma that resolved without treatment. There were some similarities between Auran's case and ours. Both cases had a clinical picture of vortex keratopathy and an Ig-kappa spike on serum electrophoresis. Auran's case differed in that the patient had decreased vision and glare, while our patient only had decreased vision without glare or photophobia. Their patient had crystalline deposits in the epithelium and stroma, while our patient had deposition only in the epithelium.

Chong et $\mathrm{al}^{34}$ described the second case of vortex keratopathy in multiple myeloma. Their case was diagnosed with multiple myeloma 18 months after first presentation to the ophthalmologist. Again, they did not obtain a corneal biopsy. They did, however, take conjunctival specimens which stained monoclonally for IgG-kappa light chains. Conjunctival electron microscopy showed intracellular hexagonal crystalline structures - similar to our corneal biopsy picture. Their conjunctival specimen also showed some extracellular material in the form of microfibrils, which stained for kappa light chains. This was not evident in our case. Chong et al therefore assumed that the corneal crystalline vortex keratopathy was due to Ig deposition.

Buerk and $\mathrm{Tu}^{35}$ reported a patient with multiple myeloma crystalline keratopathy where confocal microscopy showed in vivo crystals in the corneal epithelium and the anterior stroma. They repeated confocal microscopy after 6 months of chemotherapy and demonstrated a decrease in the size and the number of the corneal crystals. Use of in vivo confocal microscopy was also used by Paladini et $a l^{36}$ in a case with bilateral crystalline corneal deposits, due to monoclonal gammopathy. Confocal microscopy has the advantage of being able to image corneal crystalline deposits in vivo and help monitor a decrease in these changes with chemotherapy more quantitatively. However, confocal microscopy is not a histological tissue test and, therefore, cannot confirm the type 
of material/Ig deposited. We did not have access to confocal microscopy at our center.

Our case is, therefore, the first published case of vortex keratopathy in multiple myeloma with corneal deposition of Ig confirmed by corneal epithelial biopsy.

It is very rare for multiple myeloma to present in this fashion. There are several causes of intracorneal crystalline deposits, and the differentiation is impossible clinically, but laboratory studies - specifically a serum protein electrophoresis - will help detect any unsuspected multiple myeloma. ${ }^{37}$ Ophthalmologists should be aware that such a presentation may rarely be due to systemic multiple myeloma.

\section{Disclosure}

The authors report no conflicts of interest in this work.

\section{References}

1. Oglesby RB. Corneal opacities in a patient with cryoglobulinemia and reticulohistiocytosis. Arch Ophthalmol. 1961;65:63-66.

2. Kremer I, Wright P, Merin S, Weiss J, Pick Al, Kaufman H. Corneal subepithelial monoclonal kappa IgG deposits in essential cryoglobulinemia. Br J Ophthalmol. 1989;73(8):669-673.

3. Masson C, Cissé I, Simon V, Insalaco P, Audran M. Fabry disease: a review. Joint Bone Spine. 2004;71(5):381-383.

4. Hollander DA, Aldave AJ. Drug-induced corneal complications. Curr Opin Ophthalmol. 2004;15(6):541-548.

5. Chew E, Ghosh M, McCulloch C. Amiodarone-induced cornea verticillata. Can J Ophthalmol. 1982;17(3):96-99.

6. Beebe WE, Webster RG Jr, Spencer WB. Atypical corneal manifestations of multiple myeloma. A clinical, histopathologic, and immunohistochemical report. Cornea. 1989;8(4):274-280.

7. Garibaldi DC, Gottsch J, de la Cruz Z, Haas M, Green WR. Immunotactoid keratopathy: a clinicopathologic case report and a review of reports of corneal involvement in systemic paraproteinemias. Surv Ophthalmol. 2005;50(1):61-80.

8. Barr CC, Gelender H, Font RL. Cornea crystalline deposits associated with dysproteinemia. Report of two cases and review of the literature. Arch Ophthalmol. 1980;98(5):884-889.

9. Parghi C, Mcknight GT, Pflugfelder SC. Prominent corneal nerves in a patient with multiple myeloma. Cornea. 2007;26(2):220-222.

10. Perry HD, Donnenfeld ED, Font RL. Intraepithelial corneal immunoglobulin crystals in IgG-kappa multiple myeloma. Cornea. 1993;12(5): 448-450.

11. Klintworth GK, Bredehoeft SJ, Reed JW. Analysis of corneal crystalline deposits in multiple myeloma. Am J Ophthalmol. 1978;86(3): 303-313.

12. Wakita M, Kanai A, Nakajima A, Shirai T, Saionji K. [Corneal crystalline deposits in multiple myeloma]. Nippon Ganka Gakkai Zasshi. 1989;93(6):665-675. Japanese [with English abstract].

13. Felipe AF, Nottage JM, Rapuano CJ. Recurrent bilateral subconjunctival hemorrhage as an initial presentation of multiple myeloma. Oman $J$ Ophthalmol. 2012;5(2):133-134.

14. Lim LT, Ramamurthi S, Collins CE, Mantry S. Peripheral ulcerative keratitis associated with multiple myeloma. Ann Acad Med Singapore. 2011;40(12):550-551.
15. Wilson KS, Alexander S, Chisholm IA. Band keratopathy in hypercalcemia of myeloma. Can Med Assoc J. 1982;126(11):1314.

16. Gahl WA, Kuehl EM, Iwata F, Lindblad A, Kaiser-Kupfer MI. Corneal crystals in nephropathic cystinosis: natural history and treatment with cysteamine eyedrops. Mol Genet Metab. 2000;71(1-2):100-120.

17. Weiss JS, Khemichian AJ. Differential diagnosis of Schnyder corneal dystrophy. Dev Ophthalmol. 2011;48:67-96.

18. Scott CR. The genetic tyrosinemias. Am J Med Genet C Semin Med Genet. 2006;142C(2):121-126.

19. Crystalline keratopathy: spectrum of disease, diagnosis and treatment [webpage on the Internet]. San Francisco, CA, USA: American Academy of Ophthalmology EyeNet Magazine; 2008 [cited January 1, 2018]. Available from: http://www.aao.org/aao/publications/eyenet/200801/ pearls.cfm. Accessed April 28, 2013.

20. Steuhl KP, Knorr M, Rohrbach JM, Lisch W, Kaiserling E, Thiel HJ. Paraproteinemic corneal deposits in plasma cell myeloma. Am J Ophthalmol. 1991;111(3):312-318.

21. Henderson DW, Stirling JW, Lipsett J, Rozenbilds MA, RobertsThomson PJ, Coster DJ. Paraproteinemic crystalloidal keratopathy: an ultrastructural study of two cases, including immunoelectron microscopy. Ultrastruct Pathol. 1993;17(6):643-668.

22. Knapp AJ, Gartner S, Henkind P. Multiple myeloma and its ocular manifestations. Surv Ophthalmol. 1987;31(5):343-351.

23. Hill JC, Mulligan GP. Subepithelial corneal deposits in IgG lambda myeloma. Br J Ophthalmol. 1989;73(7):552-554.

24. Garner A, Kirkness CM. Corneal gammopathy. Cornea. 1988;7(1): 4449.

25. Sekundo W, Seifert P. Monoclonal corneal gammopathy: topographic considerations. Ger J Ophthalmol. 1996;5(5):262-267.

26. Francois J, Rabaey M. Corneal dystrophy and paraproteinemia. Am J Ophthalmol. 1961;52:895-901.

27. Green ED, Morrison LK, Love PE, et al. A structurally aberrant immunoglobulin paraprotein in a patient with multiple myeloma and corneal crystals deposits. Am J Med. 1990;88(3):304-311.

28. Stirling JW, Henderson DW, Rozenbilds MA, Skinner JM, Filipic M. Crystalloidal paraprotein deposits in the cornea: an ultrastructural study of two new cases with tubular crystalloids that contain IgG kappa light chains and IgG gamma heavy chains. Ultrastruct Pathol. 1997;21(4): 337-344.

29. Laibson P, Damiano V. X-ray and electron diffraction of ocular and bone marrow crystals in paraproteinemia. Science. 1969;163(3867): $581-583$.

30. Kawamura H, Seo T, Watanabe I, Ito I, Shirasawa H, Muranaka Y. [A case of corneal crystalline deposits associated with multiple myeloma]. Nihon Ganka Gakkai Zasshi. 1988;92(9):1473-1478. Japanese.

31. Yamamoto T, Hishida A, Honda N, Ito I, Shirasawa H, Nagase M. Crystal-storing histiocytosis and crystalline tissue deposition in multiple myeloma. Arch Pathol Lab Med. 1991;115(4):351-354.

32. Auran JD, Donn A, Hyman GA. Multiple myeloma presenting as vortex crystalline keratopathy and complicated by endocapsular hematoma. Cornea. 1992;11(6):584-585.

33. Høisen H, Ringvold A, Kildahl-Andersen O. Corneal crystalline deposits in multiple myeloma. A case report. Acta Ophthalmol (Copenh). 1983;61(3):493-500.

34. Chong EM, Campbell RJ, Bourne WM. Vortex keratopathy in a patient with multiple myeloma. Cornea. 1997;16(5):592-594.

35. Buerk BM, Tu E. Confocal microscopy in multiple myeloma crystalline keratopathy. Cornea. 2002;21(6):619-620.

36. Paladini I, Pieretti G, Giuntoli M, Abbruzzese G, Menchini U, Mencucci R. Crystalline corneal deposits in monoclonal gammopathy: in-vivo confocal microscopy. Semin Ophthalmol. 2013;28(1): 37-40.

37. Robertson DM. Non-cancerous ophthalmic clues to non-ocular cancer. Surv Ophthalmol. 2002;47(5):397-430. 
Clinical Ophthalmology

\section{Publish your work in this journal}

Clinical Ophthalmology is an international, peer-reviewed journal covering all subspecialties within ophthalmology. Key topics include: Optometry; Visual science; Pharmacology and drug therapy in eye diseases; Basic Sciences; Primary and Secondary eye care; Patien Safety and Quality of Care Improvements. This journal is indexed on

PubMed Central and CAS, and is the official journal of The Society of Clinical Ophthalmology (SCO). The manuscript management system is completely online and includes a very quick and fair peer-review system, which is all easy to use. Visit http://www.dovepress.com/ testimonials.php to read real quotes from published authors. 